University of Nebraska - Lincoln

DigitalCommons@University of Nebraska - Lincoln

Publications, Agencies and Staff of the U.S.

Department of Commerce

U.S. Department of Commerce

2011

\title{
High species density patterns in macrofaunal invertebrate communities in the marine benthos
}

John Oliver

Moss Landing Marine Laboratories

Kamille Hammerstrom

Moss Landing Marine Laboratories, khammerstrom@mlml.calstate.edu

Erika McPhee-Shaw

Moss Landing Marine Laboratories

Peter Slattery

Moss Landing Marine Laboratories

James Oakden

Moss Landing Marine Laboratories

See next page for additional authors

Follow this and additional works at: https://digitalcommons.unl.edu/usdeptcommercepub

Part of the Environmental Sciences Commons

Oliver, John; Hammerstrom, Kamille; McPhee-Shaw, Erika; Slattery, Peter; Oakden, James; Kim, Stacy; and Hartwell, S. Ian, "High species density patterns in macrofaunal invertebrate communities in the marine benthos" (2011). Publications, Agencies and Staff of the U.S. Department of Commerce. 300.

https://digitalcommons.unl.edu/usdeptcommercepub/300

This Article is brought to you for free and open access by the U.S. Department of Commerce at DigitalCommons@University of Nebraska - Lincoln. It has been accepted for inclusion in Publications, Agencies and Staff of the U.S. Department of Commerce by an authorized administrator of DigitalCommons@University of Nebraska - Lincoln. 


\section{Authors}

John Oliver, Kamille Hammerstrom, Erika McPhee-Shaw, Peter Slattery, James Oakden, Stacy Kim, and S. lan Hartwell 
SPECIAL TOPIC

\title{
High species density patterns in macrofaunal invertebrate communities in the marine benthos
}

\author{
John Oliver ${ }^{1}$, Kamille Hammerstrom ${ }^{1}$, Erika McPhee-Shaw ${ }^{1}$, Peter Slattery ${ }^{1}$, James Oakden ${ }^{1}$, Stacy \\ $\mathrm{Kim}^{1}$ \& S. Ian Hartwell ${ }^{2}$ \\ 1 Moss Landing Marine Laboratories, Moss Landing, CA, USA \\ 2 NOAA, Center for Coastal Monitoring \& Assessment, Silver Spring, MO, USA
}

\begin{abstract}
Keywords
Diversity; dominance; infauna; marine benthos; species density; species-area relationships.
\end{abstract}

\section{Correspondence \\ Kamille K. Hammerstrom, Moss Landing Marine Laboratories, 8272 Moss Landing Road, Moss Landing, CA, USA 95039. \\ E-mail: khammerstrom@mlml.calstate.edu}

Accepted: 4 May 2011

doi:10.1111/j.1439-0485.2011.00461.x

\begin{abstract}
Species density of macrofaunal invertebrates living in marine soft sediments was highest at the shelf-slope break $(100-150 \mathrm{~m})$ in Monterey Bay $\left(449 \mathrm{~m}^{-2}\right)$. There were 337 species $\mathrm{m}^{-2}$ in the mid-shelf mud zone $(80 \mathrm{~m})$. There were fewer species along the slope: $205 \mathrm{~m}^{-2}$ from the lower slope (950-2000 m) and $335 \mathrm{~m}^{-2}$ on the upper slope $(250-750 \mathrm{~m})$. Species density was highest inside the bay $\left(328-446 \mathrm{~m}^{-2}\right)$ compared to outside $\left(336-339 \mathrm{~m}^{-2}\right)$, when examining samples at selected water depths $(60-1000 \mathrm{~m})$. There was little difference in local species density from $1 \mathrm{~km}$ of shoreline compared to regional species density along $1000 \mathrm{~km}$ of shoreline at both shelf and slope depths. The highest species densities worldwide in the literature are recorded along the Carolina slope in the Atlantic Ocean, where peak species density $\left(436 / 0.81 \mathrm{~m}^{2}\right)$ at $800 \mathrm{~m}$ and values at the largest sample areas are similar to those on the Monterey Bay shelf. We speculate that the highest species densities occur where ocean water exchanges energy with shoaling topography at the continental margin, bringing more food to the benthos - areas such as the very productive waters in the upwelling system of Monterey Bay.
\end{abstract}

\section{Introduction}

Early ecologists wanted a term, or index, for species diversity that could reflect the complexity of biological interactions in a community and searched for models to embody this concept, settling on the idea that a community with a more even distribution of individuals among species allowed for a greater probability of interspecific encounters and was therefore more diverse. They borrowed the Shannon-Wiener (Weaver) equation $\left(\mathrm{H}^{\prime}\right)$ from information theory with a questionable analogy to interspecific encounter (Goodman 1975). H' became the most commonly cited measure of species diversity. Goodman (1975) reviewed the history of this measure and put into words what it does to the number of species and individuals: 'The Shannon-Weaver measure of species diversity is the negative logarithm of the geometric mean of the probability per individual of correctly guessing, in sequence, the species identity of each individual in a random ordering of an assortment of individuals whose relative species frequencies are given by $\left\{\mathrm{p}_{1}\right\}$, when the 'guess' is carried out by picking some arbitrary ordering of this assortment of individuals'. He concluded: 'It is a dubious index. Whatever the index does measure seems to have no direct biological interpretation'. The measure of evenness $(\mathrm{J})$, derived from $\mathrm{H}^{\prime}$, suffers from the same problem. Hurlbert (1971) thought that the effort to represent the complexity of interactions in an encounter index and the use of H' rendered species diversity a nonconcept. He provided a realistic index of the probability of interspecific encounter (PIE), which H' was supposed to be, but was not. Hurlbert urged that PIE not be used as another measure of species diversity, but instead be called what it was, an index of interspecific encounter. 
Apparently few ecologists embraced the wisdom of Hurlbert's warnings. The effort to capture the complexity of biological interactions in a single index was doomed from the start. Since then the ambiguous 'species diversity' has engulfed the more general term diversity. It is now common for a mix of measures to be called species diversity, diversity, and richness and for the terms to be used interchangeably so that it is difficult to know what is actually being measured and presented (Spellerberg \& Fedor 2003).

The two components of species diversity, richness and evenness, are still subsumed in the nonconcept, but are good metrics of community structure. Numerical species richness is commonly measured by the expected number of species, $\mathrm{E}\left(\mathrm{S}_{\mathrm{n}}\right)$ (Sanders 1968; Hurlbert 1971), which estimates the number of species in a given number of individuals. It was first used to compare species number from benthic samples collected with an epibenthic sled, which does not collect a known area of bottom. Although it is now widely used with quantitative samples, comparisons are rarely made from equal areas (Levin et al. 2001), which is the primary reason for collecting quantitative samples. Aerial species richness, or species density, is the number of species from a given area. It can also refer to estimates of species number, essentially species lists, representing large biogeographic regions and is often limited to particular taxonomic groups (e.g. Rex et al. 2000). Since the number of species can be positively related to the number of individuals, there is an argument that an increase in the number of species per area is the result of having more individuals in the sample (Gotelli \& Colwell 2001). Standardizing by number of individuals avoids this statistical problem. On the other hand, species-area plots show the actual number of species living in real and equal habitat areas over a range of areas, whether the number of individuals is large or small in different samples. The statistical relationship between species and individuals does not negate the reality of the species-area pattern, or the importance of comparing communities in a known spatial context. There are numerous papers expressing species number per number of individuals, despite comparing different areas of habitat. As a result, a recent contribution on continental margin biodiversity only shows patterns of numerical species richness and H' (Menot et al. 2010). It is much less common to find data on species density, particularly accumulated over a range of areas, allowing comparisons among marine benthic communities even when the basic quantitative sample unit is not the same area.

Our primary goals are to present species density patterns in benthic communities from the Northern and Central California margin, to show how these patterns differ on the shelf and adjacent slope, and to compare our results to high species densities from other locations around the world.

\section{Study Site and Methods}

We obtained estimates of soft-bottom species density and other community metrics by sampling benthic invertebrate communities in four major sampling programs along the upwelling coast of Central and Northern California (Fig. 1). Three of these programs were focused around the Monterey Bay area. In July and August 1999, samples were taken along four transects across the continental shelf and slope at water depths ranging from 10 to $2000 \mathrm{~m}$. The four transects were potential routes for an underwater telecommunications cable proposed by MCI WorldCom (ABA Consultants 2000). Wave disturbance is most severe in the nearshore (Oliver et al. 1980) so we used samples from 30 to $2000 \mathrm{~m}$ depths in our analysis (Fig. 1: MCI). Five replicate $0.1-\mathrm{m}^{2}$ grabs were collected at each water depth along each transect. At least two of the replicates were processed from each station. In April 2004 and May 2005, NOAA collected single samples $\left(0.1-\mathrm{m}^{2}\right)$ along eight transects in water depths from 80 to $950 \mathrm{~m}$ (Fig. 1: NOAA). In June 2003, single $0.1-\mathrm{m}^{2}$ samples were collected at 49 shelf stations ranging in depth from 33 to $123 \mathrm{~m}$, covering the largest geographic region of the four sampling programs. These grabs were taken for the U.S. Environmental Protection Agency's Western Environmental Monitoring and Assessment Program (WEMAP), and ranged from Point Conception to the Oregon border (Fig. 1: WEMAP). In September (2002) and October (2001, 2002, 2004-2006), one or two replicate $0.1-\mathrm{m}^{2}$ samples were collected at eight stations along the $80-\mathrm{m}$ isobath, which is in the center of the mud band along the outer shelf (Griggs \& Hein 1980). These stations, near and inside Monterey Bay, are part of a regional monitoring program (Central Coast Long-term Environmental Assessment Network, or CCLEAN; Fig. 1: CCLEAN). The four datasets are thus named MCI, NOAA, WEMAP, and CCLEAN throughout this paper and are distinguished as an easy means to discuss differences in species density as it relates to sampling effort, spatial scale, and water depth.

The macrofaunal invertebrate community was the focus of our comparison, rather than the larger megafauna, the smaller meiofauna or the microbial assemblages. Macrofaunal communities are much better sampled and described, and are the basis of all of the important past work on benthic marine diversity (e.g. Sanders 1968, 1969; Dayton \& Hessler 1972; Rex 1981, 1983; Gray et al. 1997; Levin et al. 2001; Menot et al. 2010). To date, they are the best indicator of species density for the entire 


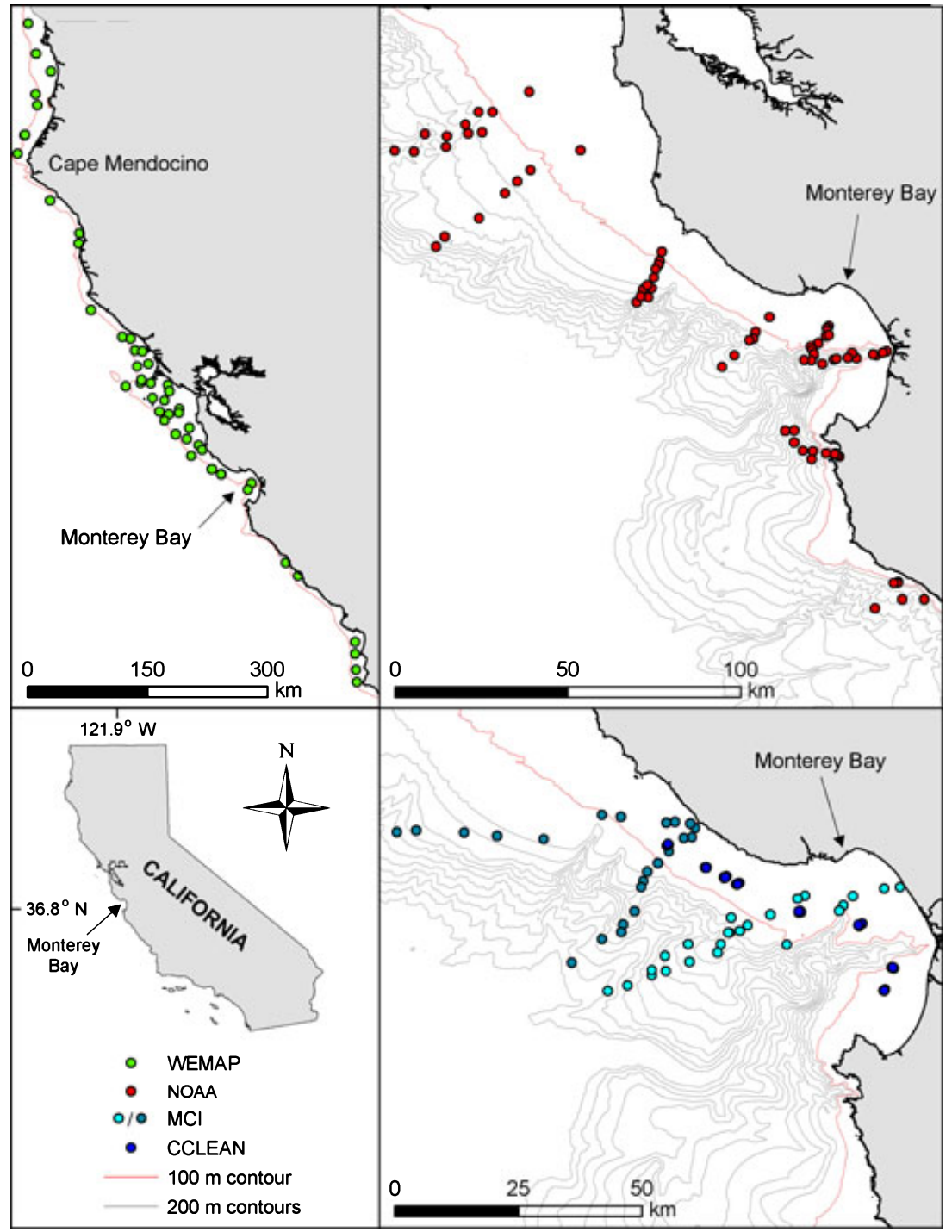

Fig. 1. Location of the four sampling projects along the Central and Northern California coast. $\mathrm{MCl}$ samples were taken along transects inside Monterey Bay (open squares) and outside the bay (filled squares).

benthic community. The megafauna (epifauna) includes far fewer species than the macrofauna and is thus a poor indicator of species density for the entire community. Meiofaunal community descriptions are too few, limited in sample area, and the taxonomy is more difficult compared to macrofauna. The species density of the microbial community has not been measured, although molecular techniques should provide realistic estimates that will allow comparisons at least among different microbial assemblages.

The $0.1-\mathrm{m}^{2}$ Smith-McIntire grab contents were washed over $0.5-\mathrm{mm}$ screens, collecting the macroinvertebrate community. Residues were preserved in $10 \%$ buffered formalin for $48-72 \mathrm{~h}$ and transferred to alcohol. Animals were sorted from the debris, identified to the lowest possible taxon, and counted. Because data were generated over several years, we updated all taxonomy prior to beginning data analysis. A $0.5-\mathrm{mm}$ screen was used along the slope rather than the smaller $0.3-\mathrm{mm}$ mesh because qualitative assessments indicated little loss of macrofaunal individuals and no loss of species, probably because of the relatively large size of the macrofauna in the California upwelling system as well as the large volume of residue that clogged the screens and likely made the effective mesh size smaller (ABA Consultants 2000). We made these assessments for the outer shelf and slope by washing samples through both screens during the MCI survey, which was done before the NOAA slope sampling. 
Despite a large number of small amphipod and other peracarid crustacean species at the shelf break, we found very few species and individuals on the smaller screen size. Along the slope, we found a few individuals of juvenile polychaetes in the $0.3-\mathrm{mm}$ residues. All of the macrofaunal species found in the $0.3-\mathrm{mm}$ screen residues were also present in the $0.5-\mathrm{mm}$ fraction of the same sample.

Computations were conducted using the PRIMER v6 software package (Clarke \& Gorley 2006). Smoothed species accumulation or species/area curves were generated using 999 random sample permutations for all projects combined and various subsets of samples by depth. PRIMER'S DIVERSE routine was used to calculate numbers of individuals, numbers of species, and Shannon-Wiener, Chaol and Simpson's dominance $(\lambda)$ indices for each sample. Means of indices were then calculated for all data and various subsets of samples by depth. Rarefaction curves were created in ECOSIM Professional v1.0 (Gotelli \& Entsminger 2011).

Data from two Monterey Bay MCI transects inside the bay (Fig. 1) were used to generate a local estimate of species-area patterns to compare with samples collected over the entire geographic range of the four datasets (regional estimate). Because replication within transects was not identical, we used a subset of the data with equal replication throughout common water depths for both the local and regional comparisons $(60,90,109,150,450,700$, $1000 \mathrm{~m}$ ). The local samples were collected along a $1-\mathrm{km}$ section of the shoreline. The regional samples were selected from the entire study area along $1000 \mathrm{~km}$ of shoreline. Data for regional curves were selected using Hawth's Analysis Tools for ARCGIS to randomly select sample positions in the appropriate depth range (30-150, 250-2000 m; Beyer 2004). In cases where multiple replicates were collected at a sample position (MCI, CCLEAN), a single replicate was randomly selected for use in the regional dataset.

\section{Results and Discussion}

California upwelling system

There were distinct changes in species density among the four sampling programs, inside and outside Monterey Bay, and especially with water depth. The number of macrofaunal species in soft-bottom communities was highest on the continental shelf when all four datasets were combined (Fig. 2) and when they were examined separately (Fig. 3). The highest species density was observed at the shelf-slope break, and the lowest at deeper slope depths below the oxygen minimum zone (Fig. 2). The MCI transects in Monterey Bay had a higher species density than those sampled along the continental
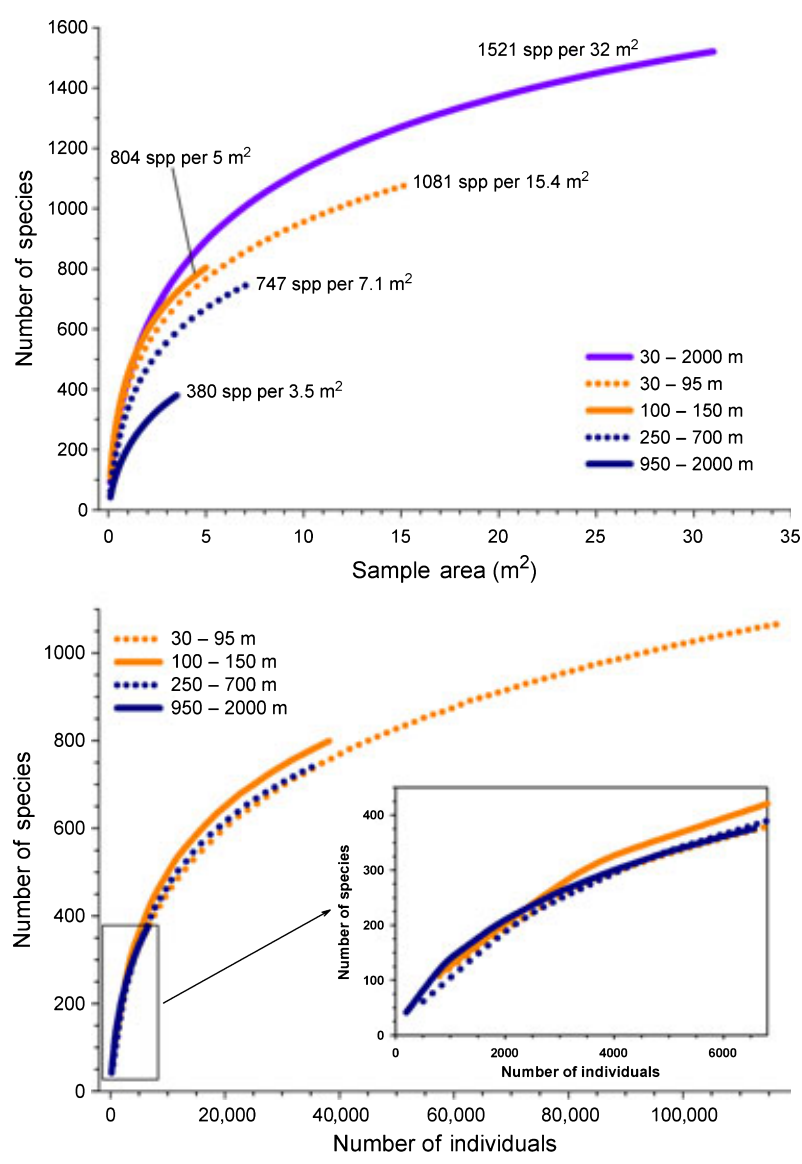

Fig. 2. Changes in species-area and rarefaction (numerical species richness) patterns in different water depths combining all four datasets. The top panel shows species-area curves for all depths and four depth ranges. The bottom panel shows rarefaction curves for four depth ranges with an inset that enlarges the area where all curves are present. Numbers next to curves in the top panel are the total species present in the largest sample area (sum of all samples for that depth range).

margin outside the bay (Fig. 4). Therefore, the Monterey Bay shelf was a local hot spot for species density, peaking at the shelf break. This pattern was not related to sampling effort in the Monterey Bay transects. The transect with the highest species density was based on 23 samples and the two transects from outside the bay were based on 26 and 20 samples (Fig. 4).

We examined each dataset separately because they represent different depth and geographic ranges (Fig. 1). Despite considerable variation in both depth and geographic area, species density was high throughout the study area (Fig. 3). However, the two datasets with the largest depth range (MCI and NOAA) had a higher number of species compared to the two programs sampling only the shelf (WEMAP and CCLEAN; Fig. 3). CCLEAN 

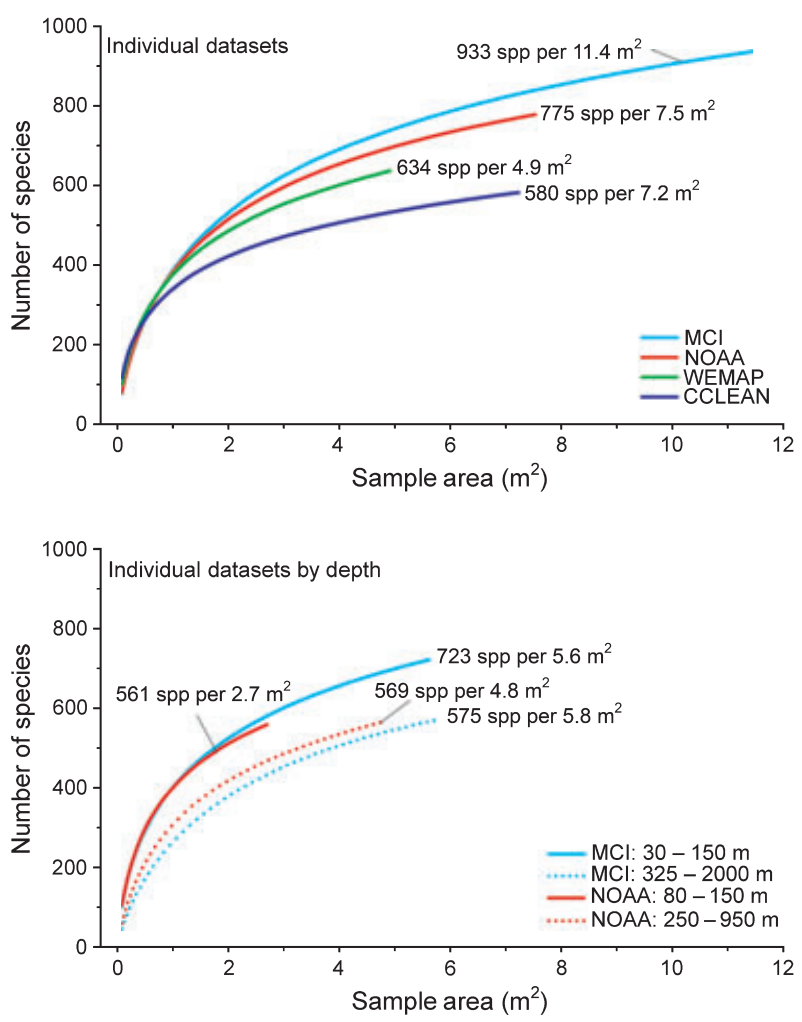

Fig. 3. Species-area patterns from each dataset (top panel) and then separated into shelf and slope depths for the two programs that sampled beyond the shelf (bottom panel, $\mathrm{MCl}$ and NOAA). Shown for each curve are the number of species present in the largest sample area (sum of all samples for that depth range).

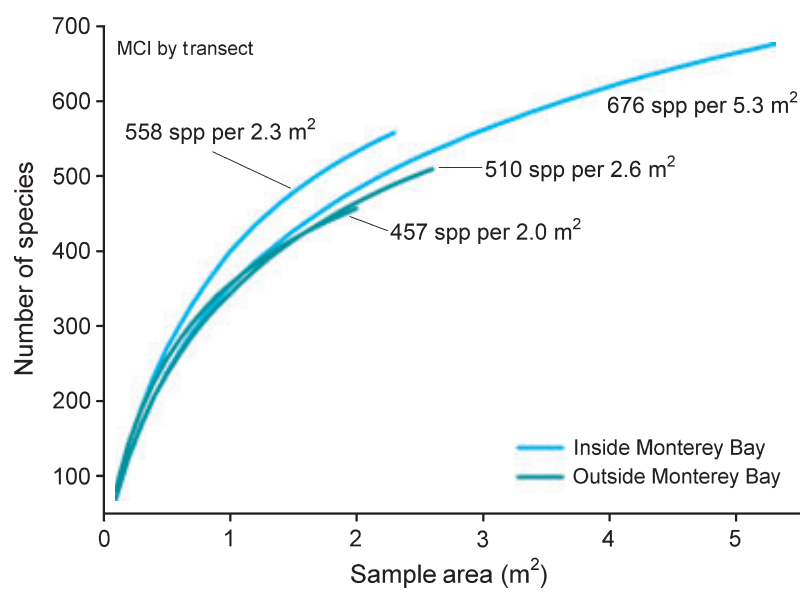

Fig. 4. Changes in species-area patterns among the four transects in the $\mathrm{MCl}$ sampling program. Data are from the same water depths on each transect. Shown for each curve are the number of species present in the total sample area.

had the lowest species number and included the fewest stations, all at one water depth $(80 \mathrm{~m})$ in the mud band (Griggs \& Hein 1980) along the shelf (Figs 1 and 3).
Unlike water depth, there was no simple relationship between the total geographic area of a sampling program and species density. WEMAP samples were dispersed over the largest geographic area, but were limited to shelf depths with only a few samples at the shelf-slope break (Fig. 1). They had the third highest species density (Fig. 3). NOAA samples were dispersed over the next largest geographic area from 80 to $950 \mathrm{~m}$ (Fig. 1). They had the second highest species density (Fig. 3). MCI samples were mostly around the Monterey Bay area, from depths of 30-2000 m (Fig. 1). They had the highest species density (Fig. 3). Finally, CCLEAN samples were dispersed over the smallest geographic region, and they had the lowest species density (Fig. 3). We also examined the impact of geographic scale by estimating species density from a local area within Monterey Bay (along a kilometer of shoreline) and from a larger regional scale along $1000 \mathrm{~km}$ of shore, selecting samples to avoid differences in sampling effort. There was little difference between our estimates of local and regional species density on the shelf or the slope (Fig. 5).

Ideally we would compare species density from the largest area possible and thus at or closer to the asymptote (relatively flat top) of the species-area curves (Gotelli \& Colwell 2001). Fortunately, the lower-bound of the expected number of species at the asymptote can be predicted with the Chaol estimator (Chao 2005). The Chaol estimators show the same general pattern of high species number on the shelf compared to the slope (Table 1). Although the Chaol estimates are interesting and support the key depth and geographic patterns, we believe the sample data, not the model predictions, are more realistic and thus accurate metrics for describing community structure and making comparisons within

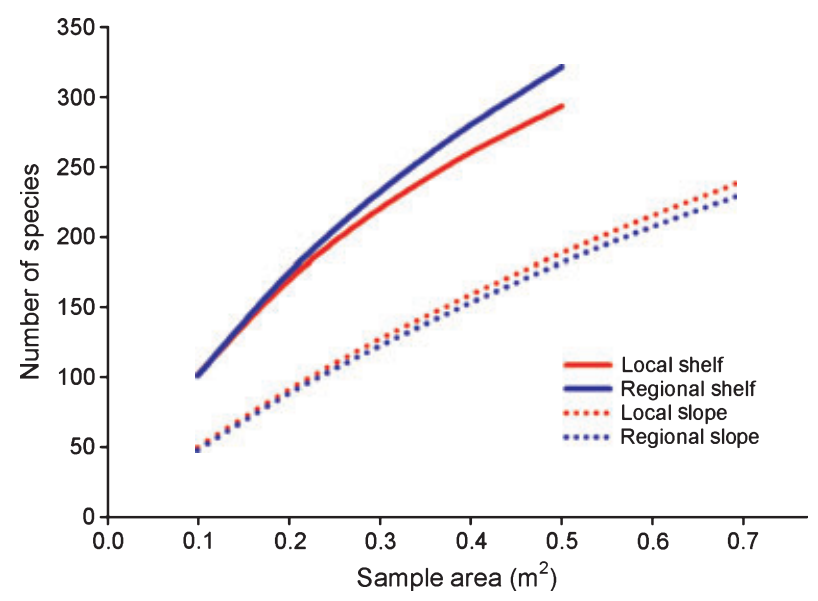

Fig. 5. Species-area patterns from local $(1 \mathrm{~km})$ and regional (1000 km) geographic sampling. 
and between communities. The species-area curves crossed only at the smallest sample areas, where there was the greatest variability between single samples. Once samples were combined, the variability was reduced at larger sample areas and the relative differences among the curves persisted to the end of each curve (e.g. Fig. 3 top panel).

The presence of an oxygen minimum zone (OMZ) did not account for the lower species density on the slope compared to the shelf. The OMZ is between 500 and $1000 \mathrm{~m}$ in the study area (Mullins et al. 1985; Johnson et al. 1992). Although oxygen levels in the Central California coastline's OMZ are relatively low compared to some upwelling regions (Levin 2003), the center of the OMZ harbored a dense community of ampeliscid amphipods, forming a tube mat that was seen in ROV video footage along all four of the MCI depth transects (Fig. 1). We sampled in the tube mat from the center of the OMZ at $700 \mathrm{~m}$ and included these samples in the upper slope, where there was relatively high species density (Fig. 2). The lowest species densities were found below the OMZ at 1000-2000 m (Fig. 2).

In addition to higher species density on the shelf, we found a significant negative correlation between the number of species and dominance per grab sample (Fig. 6). The significant correlation persisted if we separated the data into shelf $\left(\mathrm{r}^{2}=0.1\right)$ and slope $\left(\mathrm{r}^{2}=0.2, \mathrm{P}<0.0001\right.$ for both). This negative relationship is present along the wave-swept inner shelf and in local wetlands as well (Oliver et al. 2008, 2009). Since there are usually higher numbers of individuals on the shelf compared to the slope, we observed a significant positive correlation between the number of species and individuals (Fig. 6). This correlation also persisted when the data were divided into shelf $\left(r^{2}=0.6\right)$ and slope $\left(r^{2}=0.3, P<0.0001\right.$ for both $)$.

\section{Other indices}

Changes in the Shannon-Wiener index followed the same pattern as species density: higher on the shelf than the slope, highest at the shelf break, and lowest along the

Table 1. Summary statistics for the total dataset and selected depth ranges. $\mathrm{N}$ is the number of samples in each depth range. $\mathrm{S}$ is the observed total number of species. Chao1 is a total species density estimator. $\mathrm{H}^{\prime}$ is the Shannon-Wiener index and $\lambda$ is Simpson's Dominance Index.

\begin{tabular}{lrrrrc}
\hline depth range $(\mathrm{m})$ & $\mathrm{N}$ & $\mathrm{S}$ & Chao1 & $\mathrm{H}^{\prime}$ & $\lambda$ \\
\hline $30-2000$ & 310 & 1521 & 1714 & 3.420 & 0.085 \\
$30-95$ & 154 & 1081 & 1293 & 3.675 & 0.057 \\
$100-150$ & 50 & 804 & 998 & 3.680 & 0.064 \\
$250-700$ & 71 & 747 & 942 & 2.981 & 0.130 \\
$950-2000$ & 35 & 380 & 508 & 2.821 & 0.149 \\
\hline
\end{tabular}
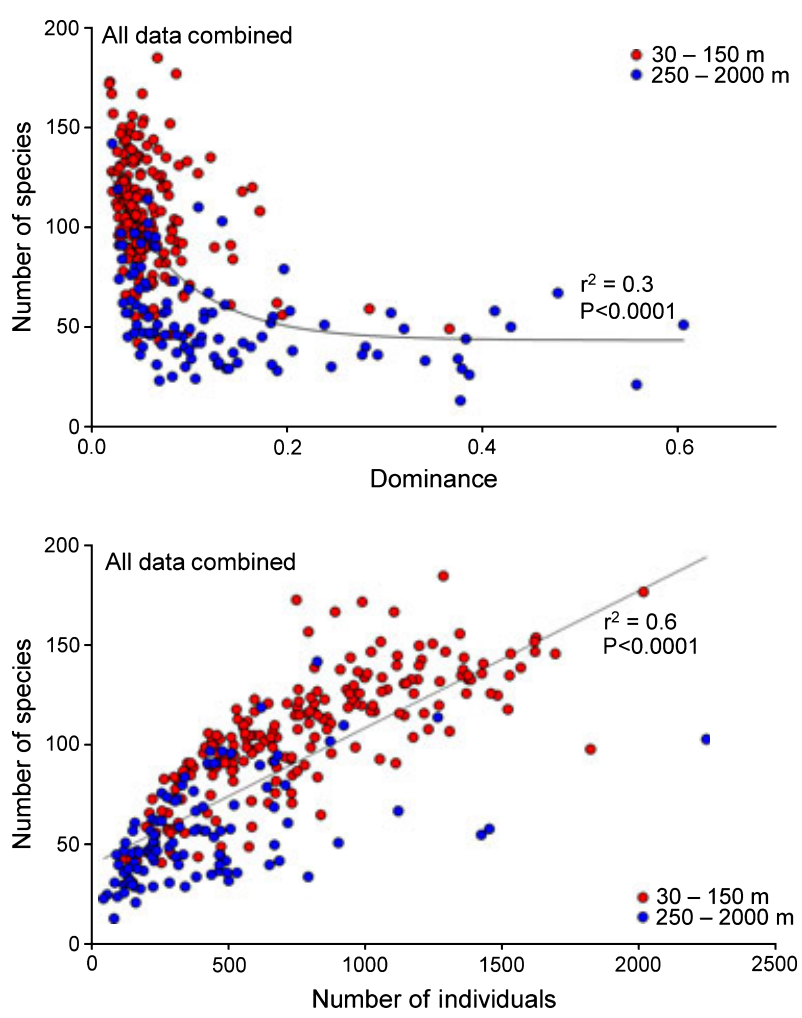

Fig. 6. The significant negative relationship between number of species and dominance and the significant positive correlation between number of species and individuals (all four datasets).

deeper slope (Table 1). Simpson's dominance was lowest on the shelf and highest in the deepest water depths sampled (Table 1). We recommend that $\mathrm{H}^{\prime}$ and $\mathrm{J}$ be retired from ecology and that other species diversity indices should be named for what they attempt to model, such as the probability of interspecific encounter (PIE), as Hurlbert (1971) recommended decades ago. Indices of dominance and evenness should be just that, and no longer components of species diversity. They are important summaries of relative abundance. Species diversity should also not be a model of the complexity of biological interactions. It should refer to the variety of species estimated by two types of structural metrics, species density and numerical species richness, with no ambiguity about which is being presented. Number of species increases with increasing habitat area in a non-linear manner, so quantitative sampling gear collects a standard area of bottom to allow direct comparisons among replicates and other sample collections. The gold standard for measuring species number should be the number per quantitative sample and thus area. Levin et al. (2001) found that species density and numerical species richness showed the same pattern with depth, but not in our sampling (Fig. 2). Although the shelf edge $(100-150 \mathrm{~m})$ had the 


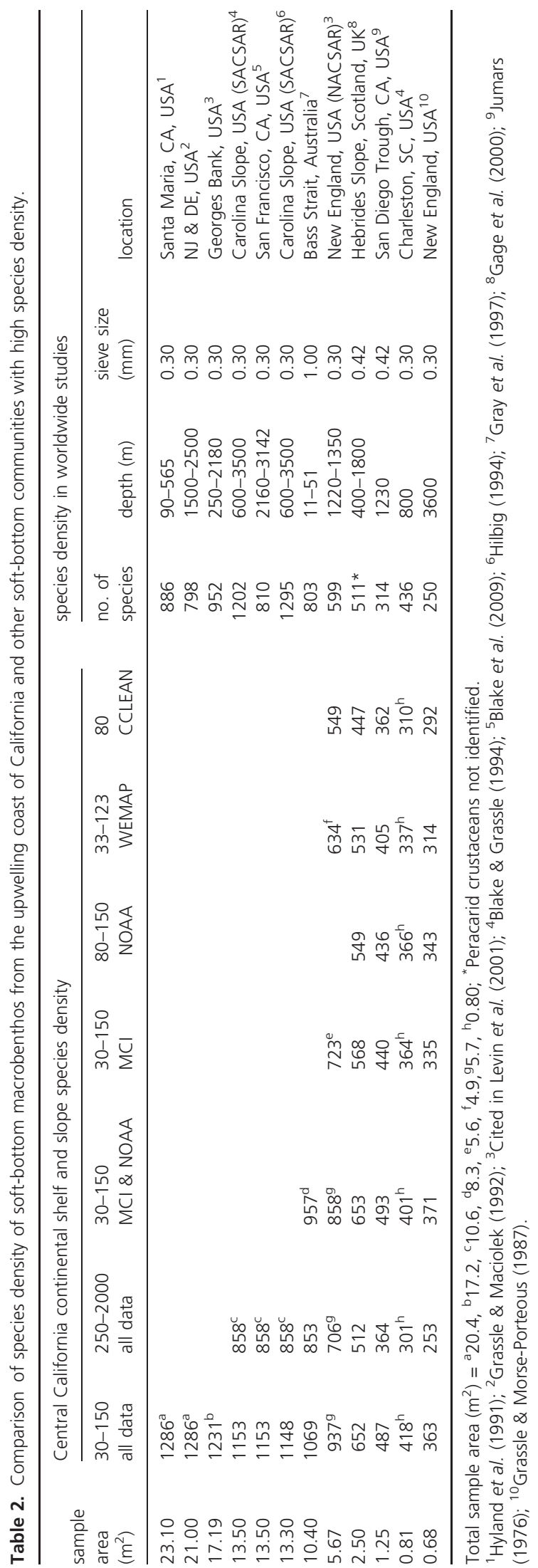

highest numerical species richness and species density, numerical richness at the other depths were quite similar (Fig. 2). Therefore, we cannot always expect numerical species richness and species density to show the same depth and geographic patterns.

Numerical species richness often peaks along the slope (Rex 1981, 1983; Levin et al. 2001), but not always (Menot et al. 2010). Species density in the deep-sea may also be high along the slope, but there are high values from the shelf as well (Table 2). Although we did not observe high species density from the slope depths we sampled (Figs 2 and 3), there are high values along the slope outside San Francisco Bay (Table 2), which is only $100 \mathrm{~km}$ north of Monterey Bay (Fig. 1). The important similarity in all these data is that the highest values (species density and numerical species richness) are along the continental margins (Table 2, Menot et al. 2010). The species density data clearly show that slope and shelf communities both have extremely high values (Table 2).

If we could shrink ourselves and walk through the benthic community as we can walk through a forest, the number of species would clearly be higher on the shelf than on the slope (Figs 2 and 3). If we walked from the scale of a sample $\left(0.1-\mathrm{m}^{2}\right)$ to the local setting and through the regional geography, the variety of species would be higher on the shelf at all spatial scales (Figs 2-5). This is not reflected in numerical species richness, which showed little difference between the shelf and slope (Fig. 2). We would also encounter a much greater number of individuals and less dominance on the shelf (Fig. 6, Table 1). A higher species density (Fig. 2), larger number of animals (Fig. 6), and greater evenness of relative abundance (Fig. 6) would lead most naturalists to conclude that the complexity of biological interactions should be higher on the shelf (all other things being equal for the walk). There is no model (probability of interspecific encounter or other) that combines these fundamental community metrics into a single metric of community complexity (structure or function) without obscuring the most important ecological realities observed during our hypothetical walk. Numerical species richness is a fine addition to the three metrics and is especially useful if we do not have samples of a standard area. If quantitative samples are taken, species density should be measured and presented in species-area curves for community descriptions. Despite the statistical inconvenience of the correlation between the number of species and individuals (Fig. 6), the most realistic community description is done in a known spatial context, especially for comparisons among samples, community patches, and different communities. 


\section{Worldwide patterns}

We compared our data with the highest species densities in soft sediments that we could find in the literature (Table 2). Species density from the continental shelf in Monterey Bay was very similar to levels reported from the Carolina slope, which has the highest species densities in the world reported to date, with a peak at $800 \mathrm{~m}$ (436/0.81 $\mathrm{m}^{2}$; Table 2). The Carolina slope has a heterogeneous bottom with dynamic currents and likely high inputs of food (Blake \& Grassle 1994). The second highest species density from the shelf was documented on the Australian side of Bass Strait between Australia and Tasmania (Gray et al. 1997). The species density was also high on the shelf and highest at the shelf break at the southern end of the California upwelling system (Hyland et al. 1991). It appears that the soft-bottom shelf communities with the highest species densities in the world were found in well-mixed and oxygenated waters with high production (Breaker \& Broenkow 1994; Pennington \& Chavez 2000; Fitzwater et al. 2003; McGinley 2008; Ryan et al. 2009). These general habitat characteristics are similar to the current-dominated Carolina slope with the highest species densities in the world (Blake \& Grassle 1994).

Escaravage et al. (2009) documented a positive relationship between species density and productivity in soft bottoms from a compiled dataset covering the European coast (primarily from the shelf). They include two studies with moderately high species density: the highest with 1033 species in $34.4 \mathrm{~m}^{2}$ from the Aegean. We found 1531 in $32 \mathrm{~m}^{2}$ (Fig. 1). There are 952 in $17.19 \mathrm{~m}^{2}$ along the Georgia Banks (Table 2), which is half the sample area from the Aegean. Table 2 does not include a number of other studies with moderately high species density (e.g. Gage 1979; Gray et al. 1997; Stora et al. 1999; Thiel et al. 2007; Dahle et al. 2009).

Differences between sampling methods and sample dispersion do not confound comparisons between our data and those from other parts of the world (Table 2). All the data in Table 2 come from quantitative samples. We are not comparing species density to numerical species richness (Abele \& Walters 1979; Gray et al. 1997). The differences in screen size do not lead to unrealistic comparisons, but some must be qualified, especially the samples from Bass Strait. We found no loss of species between the 0.5 - and $0.3-\mathrm{mm}$ screens, so our data can be compared to samples that were washed through the smaller screen (most of the data in Table 2). Samples from two of the slope sites were washed through 0.42$\mathrm{mm}$ screens, potentially losing some species that could be captured on a $0.3-\mathrm{mm}$ mesh. The samples from Scotland do not include the peracarid crustaceans, so species density should be even higher here. We include the two 0.42-mm surveys because they found high species density despite their use of a larger sieve mesh size. Bass Strait samples were dispersed over a small geographic area and depth range and washed over a 1-mm screen, which could significantly depress species density. Despite these likely losses, Bass Strait has a high species density (Table 2, Gray et al. 1997). If the sampling included the entire shelf and a $0.5-\mathrm{mm}$ screen, species density might be more similar to that in Monterey Bay and along the Carolina slope. Although there are considerable differences in the depth and geographic ranges of the data from other parts of the world, many of these differences are similar to the variation in our study, which includes samples from one depth, two depth zones on the shelf and slope, the shelf and slope combined, and several different geographic scales with different depth ranges. None of the differences discussed above invalidates the comparisons in Table 2.

\section{Boundary effects}

All of the communities with the highest species densities (Table 2) are located along continental margins, where there are dramatic changes in topography. The continental slope is probably the most extensive steep rise in topography in the ocean. The shelf-slope break is the most abrupt topographic change along the slope. Pelagic primary productivity at the ocean surface is often highest over the continental shelf and drops rapidly at the shelf break and over the slope (Kudela et al. 2008). However, we found a strikingly different pattern in benthic species density. The highest species density in our study occurred around the shelf-slope break (Fig. 2). We documented 804 species in $5 \mathrm{~m}^{2}$ (Fig. 2, top panel) collected from 100 to $150 \mathrm{~m}$. Four of the locations from other parts of the world reported about 800 species, but they were collected in sample areas that were two to four times larger than $5 \mathrm{~m}^{2}$ (Table 2).

What is it about the shelf break that might cause such high species densities? Although the continental shelf is often characterized by an accumulation of fine material (a 'shelf mud belt'), the outer shelf and upper slope usually comprise coarser grained sediments, a relict from glacial low sea stands. Oceanographers have long discussed the reasons that the relatively abrupt change in topographic steepness at the shelf break might enhance currents and frictional dissipation of long-wavelength features such as tides and low-mode internal tides (Sverdrup et al. 1942). Abrupt topographic changes such as those found on Georges Banks or on the European shelf seas can cause tidal mixing fronts and intense, rapid exchange between the sea floor and near-surface waters (Houghton \& 
Ho 2001), and a seasonal shelf-break front is a common feature of the Northeastern Atlantic (Chapman \& Lentz 1994). Although such features are not typically found over the continental shelves of California, they still serve to illustrate the sometimes dramatic changes in dynamics and energy near the shelf-slope break (see review, McPhee-Shaw 2006). Studies from the California margin demonstrate that interaction between internal tides and topography intensify cross-isobath currents over the upper continental slope and are associated with removal of fine sediments from the margin (Cacchione et al. 2002; McPhee-Shaw et al. 2004).

These variations in energy and dynamics can have an array of effects on benthic habitat. Intense up-slope and down-slope excursions associated with internal tides expose benthic organisms, which are fixed in space, to several hundred meters of vertical water column gradients of temperature and oxygen, and over brief time scales $(<12 \mathrm{~h})$. These water movements may also bring more food to the benthos. Energetic currents prevent the accumulation of fine material, and presumably allow greater penetration of oxygen and nutrients into the substrate. Thus, just as in freshwater ecosystems, where the well mixed and oxygenated gravel and mixed-substrate under medium-to-energetic streams have a much higher density of macroinvertebrates than the substrates under either very strong rivers or under the still waters of deep channels, ponds, and lakes (Karr \& Chu 1999), the shelf-slope break and upper slope may be an ideal habitat for ocean benthic communities. Although more diffuse in space and larger in scale, the shelf break and upper continental slope may be analogous to the species-rich hard-bottom communities of coral reefs and ocean pinnacles, both of which have a topography that enhances water motion and the transport of food and nutrients to the sea floor (Genin et al. 1986; Koslow 1997; Leichter et al. 1998; Genin 2004).

\section{Summary}

1 We found 1521 species of macrofaunal invertebrates in $32 \mathrm{~m}^{2}$ of bottom from the California upwelling system (Fig. 2), where soft-bottom species density is among the highest in the world (Table 2).

2 Species density was consistently higher along the shelf (30-150 m) than along the slope (250-2000 m; Figs 2 and 3 ), with the highest number of species at the shelfslope break (Fig. 2: 100-150 m) coincident with breaking internal waves and in the Monterey Bay under an upwelling plume and production hot spot (Fig. 4).

3 Numerical species richness did not show the same depth pattern as species density, which we consider the best local and regional estimate of species number.
4 There was a significant negative correlation between the number of species and dominance.

5 Species density from the California shelf is remarkably similar to that reported from the Carolina slope, at both local ( $800 \mathrm{~m}$ compared to the shelf break) and regional scales (Table 2). Species density at these two sites is considerably higher than anywhere else in the world.

\section{Acknowledgements}

Paul Dayton is a great example as a scientist and friend. He taught us the paramount importance of natural history, time series, human disruptions, laughing, and good pies. We owe thanks to Lisa Levin, Jim Blake and the anonymous reviewers, Coastal Conservation and Research Inc. for producing the WEMAP data, ABA Consultants for providing the CCLEAN and MCI data, Rusty Fairey and Ivano Aiello at Moss Landing Marine Labs, and Steve Weisberg and Ananda Ranasinghe of the Southern California Coastal Water Research Project. We are most grateful to the many invertebrate taxonomists who make our estimates of community structure possible: Kelvin Barwick (Mollusca), Don Cadien (Crustacea), Hank Chaney (Gastropoda), Matt Forrest (Ectoprocta), Leslie Harris (Polychaeta), Gordon Hendler (Ophiuroidea), Mike Kellogg (Mollusca), Louis Kornicker (Ostracoda), Linda Kuhnz (Mollusca), Gretchen Lambert (Ascidacea), Welton Lee (Porifera), Megan Lilly (Ophiuroidea), John Ljubenkov (Cnidaria), Josh Mackie (Oligochaeta), Tony Phillips (Nemertea), Gene Ruff (Polychaeta), Paul Valentich-Scott (Mollusca). We would also like to thank the many students and staff who assisted in fieldwork, sample processing, and sorting.

\section{References}

ABA Consultants (2000) MCI/Worldcom Southern Cross Monterey Bay Cable Landing, Technical Memorandum 5. Offshore Studies: Physical Oceanography and Marine Biology. Prepared for Natural Resources Consultants, CA, 207 pp.

Abele L.G., Walters K. (1979) Marine benthic diversity: a critique and alternative explanation. Journal of Biogeography, $\mathbf{6}$, 115-126.

Beyer H.L. (2004) Hawth's Analysis Tools for ArcGIS. http:// www.spatialecology.com/htools.

Blake J.A., Grassle J.F. (1994) Benthic community structure on the US South Atlantic slope off the Carolinas: spatial heterogeneity in a current-dominated system. Deep-Sea Research Part II, 41, 835-874.

Blake J.A., Maciolek N.J., Ota A.Y., Williams I.P. (2009) Longterm benthic infaunal monitoring at a deep-ocean dredged material disposal site off Northern California. Deep-Sea Research Part II, 56, 1775-1803. 
Breaker L.C., Broenkow W.W. (1994) The circulation of Monterey Bay and related processes. Oceanography and Marine Biology: An Annual Review, 32, 1-64.

Cacchione D.A., Pratson L.F., Ogston A.S. (2002) The shaping of continental slopes by internal tides. Science, 296, 724-727.

Chao A. (2005) Species estimation and applications. In: Balakrishnan N., Read C.B., Vidakovic B. (Eds), Encyclopedia of Statistical Sciences, 2nd edn. 12, 7907-7916. Wiley, New York.

Chapman D.C., Lentz S.J. (1994) Trapping of a coastal density front by the bottom boundary layer. Journal of Physical Oceanography, 24, 1464-1479.

Clarke K.R., Gorley R.N. (2006) PRIMER v6: User Manual/ Tutorial. PRIMER-E, Plymouth.

Dahle S., Anisimova N.A., Palerud R., Renaud P.E., Pearson T.H., Matishov G.G. (2009) Macrobenthic fauna of the Franz Josef Land archipelago. Polar Biology, 32, 169-180.

Dayton P.K., Hessler R.R. (1972) Role of biological disturbance in maintaining diversity in the deep sea. Deep-Sea Research, 19, 199-208.

Escaravage V., Herman P.M.J., Merckx B., Wlodarska-Kowalczuk M., Amouroux J.M., Degraer S., Grémare A., Heip C.H.R., Hummel H., Karakassis I., Labrune C., Willems W. (2009) Distribution patterns of macrofaunal species diversity in subtidal soft sediments: biodiversity-productivity relationships from the MacroBen database. Marine Ecology Progress Series, 382, 253-264.

Fitzwater S.E., Johnson K.S., Elrod V.A., Ryan J.P., Coletti L.J., Tanner S.J., Gordon R.M., Chavez F.P. (2003) Iron, nutrient and phytoplankton biomass relationships in upwelled waters of the California coastal system. Continental Shelf Research, 23, 1523-1544.

Gage J.D. (1979) Macrobenthic community structure in the Rockall Trough. Ambio Special Report, 6, 43-46.

Gage J.D., Lamont P.A., Kroeger K., Paterson G.L.J., Gonzalez Vecino J.L. (2000) Patterns in deep-sea macrobenthos at the continental margin: standing crop, diversity, and faunal change on the continental slope off Scotland. Hydrobiologia, 440, 261-271.

Genin A. (2004) Bio-physical coupling in the formation of zooplankton and fish aggregations over abrupt topographies. Journal of Marine Systems, 50, 3-20.

Genin A., Dayton P.K., Lonsdale P.F., Spiess F.N. (1986) Corals on seamount peaks provide evidence of current acceleration over deep-sea topography. Nature, 322, 59-61.

Goodman D. (1975) The theory of diversity-stability relationships in ecology. Quarterly Review of Biology, 50, 237-266.

Gotelli N.J., Colwell R.K. (2001) Quantifying biodiversity: procedures and pitfalls in the measurement and comparison of species richness. Ecology Letters, 4, 379-391.

Gotelli N.J., Entsminger G.L. (2011) EcoSim Professional: Null Modeling Software For Ecologists. Version 1.0. Acquired Intelligence Inc., Kesey-Bear \& Pinyon Publishing, Jerico, VT, USA. http://www.garyentsminger.com/ecosim/index.htm.
Grassle J.F., Maciolek N.J. (1992) Deep-sea species richness: regional and local diversity estimates from quantitative bottom samples. American Naturalist, 139, 313-341.

Grassle J.F., Morse-Porteous L.S. (1987) Macrofaunal colonization of disturbed deep-sea environments and the structure of deep-sea benthic communities. Deep-Sea Research Part II, 34, 1911-1950.

Gray J.S., Poore G.C.B., Ugland K.I., Wilson R.S., Olsgard F., Johannessen $\varnothing$. (1997) Coastal and deep-sea benthic diversities compared. Marine Ecology Progress Series, 159, 97-103.

Griggs G.B., Hein J.R. (1980) Sources, dispersal, and clay mineral composition of fine-grained sediments off central and northern California. Journal of Geology, 88, 541-566.

Hilbig B. (1994) Faunistic and zoogeographical characterization of the benthic infauna on the Carolina continental slope. Deep-Sea Research Part II, 41, 929-950.

Houghton R.W., Ho C. (2001) Diapycnal flow through the Georges Bank tidal front: a dye tracer study. Geophysical Research Letters, 28, 33-36.

Hurlbert S.H. (1971) The nonconcept of species diversity: a critique and alternative parameters. Ecology, 52, 577-586.

Hyland J., Baptiste E., Campbell J., Kennedy J., Kropp R., Williams S. (1991) Macroinfaunal communities of the Santa Maria Basin on the California outer continental shelf and slope. Marine Ecology Progress Series, 78, 147-161.

Johnson K.S., Berelson W.M., Coale K.H., Coley T.L., Elrod V.A., Fairey W.R., Iams H.D., Kilgore T.E., Nowicki J.L. (1992) Manganese flux from continental margin sediments in a transect through the oxygen minimum. Science, 257, $1242-1245$.

Jumars P.A. (1976) Deep-sea species diversity: does it have a characteristic scale? Journal of Marine Research, 34, 217246.

Karr J.R., Chu E.W. (1999) Restoring Life in Running Waters: Better Biological Monitoring. Island Press, Washington, DC: 206 pp.

Koslow J.A. (1997) Seamounts and the ecology of deep-sea fisheries. American Scientist, 85, 168-176.

Kudela R.M., Banas N.S., Barth J.A., Frame E.R., Jay D., Largier J.L., Lessard E.J., Peterson T.D., Vander Woude A.J. (2008) New insights into the controls and mechanisms of plankton productivity along the US West Coast. Oceanography, 21, 46-59.

Leichter J.J., Shellenbarger G., Genovese S.J., Wing S.R. (1998) Breaking internal waves on a Florida (USA) coral reef: a plankton pump at work? Marine Ecology Progress Series, 166, 83-97.

Levin L.A. (2003) Oxygen minimum zone benthos: adaptation and community response to hypoxia. Oceanography and Marine Biology: an Annual Review, 41, 1-45.

Levin L.A., Etter R.J., Rex M.A., Gooday A.J., Smith C.R., Pineda J., Stuart C.T., Hessler R.R., Pawson D. (2001) Environmental influences on regional deep-sea species diversity. Annual Review of Ecology and Systematics, 32, 51-93. 
McGinley M. (2008) Southeast Australian Shelf large marine ecosystem. In: Cleveland C.J. (Ed), Encyclopedia of Earth. Environmental Information Coalition, National Council for Science and the Environment, Washington, DC: http:// www.eoearth.org/article/Southeast_Australian_Shelf_large_ marine_ecosystem.

McPhee-Shaw E.E. (2006) Boundary-interior exchange: reviewing the idea that internal-wave mixing enhances lateral dispersal near continental margins. Deep-Sea Research Part II, 53, 42-59.

McPhee-Shaw E.E., Sternberg R.W., Mullenbach B., Ogston A.S. (2004) Observations of intermediate nepheloid layers on the northern California margin. Continental Shelf Research, 24, 693-720.

Menot L., Sibuet M., Carney R.S., Levin L.A., Rowe G.T., Billett D.S.M., Poore G., Kitazato H., Vanreusel A., Galéron J., Lavrado H.P., Sellanes J., Ingole B., Krylova E. (2010) New perceptions of continental margin biodiversity. In: McIntyre A.D. (Ed), Life in the World's Oceans: Diversity, Distribution, and Abundance. Wiley-Blackwell, UK: 79-101.

Mullins H.T., Thompson J.B., McDougall K., Vercoutere T.L. (1985) Oxygen-minimum zone edge effects: evidence from the central California coastal upwelling system. Geology, 13, 491-494.

Oliver J.S., Slattery P.N., Hulberg L.W., Nybakken J.W. (1980) Relationships between wave disturbance and zonation of benthic invertebrate communities along a high-energy subtidal beach in Monterey Bay, California. Fishery Bulletin, 78, 437-454.

Oliver J.S., Kim S.L., Slattery P.N., Oakden J.M., Hammerstrom K.K., Barnes E.M. (2008) Sandy bottom communities at the end of a cold (1971-1975) and warm regime (19971998) in the California Current: impacts of high and low plankton production. Available from Nature Precedings. $<$ http://dx.doi.org/10.1038/npre.2008.2103.1>.

Oliver J.S., Hammerstrom K.K., Aiello I.W., Oakden J.M., Slattery P.N., Kim S.L. (2009) Benthic invertebrate communities in peripheral wetlands of Elkhorn Slough ranging from very restricted to well-flushed by tides. Final report to Monterey Bay National Marine Sanctuary and Elkhorn Slough National Estuarine Research Reserve, CA, 77 pp.

Pennington J.T., Chavez F.P. (2000) Seasonal fluctuations of temperature, salinity, nitrate, chlorophyll and primary production at station H3/M1 over 1989-1996 in Monterey Bay, California. Deep-Sea Research Part II, 47, 947-973.
Rex M.A. (1981) Community structure in the deep-sea benthos. Annual Review of Ecology and Systematics, 12, 331353.

Rex M.A. (1983) Geographic patterns of species diversity in deep-sea benthos. In: Rowe G.T. (Ed.), The Sea, 8, 453-472.

Rex M.A., Stuart C.T., Coyne G. (2000) Latitudinal gradients of species richness in the deep-sea benthos of the North Atlantic. Proceedings of the National Academy of Sciences, 97, 4082-4085.

Ryan J.P., Fischer A.M., Kudela R.M., Gower J.F.R., King S.A., Marin R., Chavez F.P. (2009) Influences of upwelling and downwelling winds on red tide bloom dynamics in Monterey Bay, California. Continental Shelf Research, 29, 785-795.

Sanders H.L. (1968) Marine benthic diversity: a comparative study. American Naturalist, 102, 243-282.

Sanders H.L. (1969) Marine benthic diversity and the stabilitytime hypothesis. In: Woodwell G.G., Smith H.H. (Eds), Diversity and Stability in Ecological Systems. Brookhaven Symposia in Biology, 22, 71-81.

Spellerberg I.F., Fedor P.J. (2003) A tribute to Claude Shannon (1916-2001) and a plea for more rigorous use of species richness, species diversity and the 'Shannon-Wiener' index. Global Ecology \& Biogeography, 12, 177-179.

Stora G., Bourcier M., Arnoux A., Gerino M., Le Campion J., Gilbert F., Durbec J.P. (1999) The deep-sea macrobenthos on the continental slope of the northwestern Mediterranean Sea: a quantitative approach. Deep-Sea Research Part I, 46, 1339-1368.

Sverdrup H., Johnson M.W., Fleming R.H. (1942) The Oceans - their Physics, Chemistry, and General Biology. Prentice-Hall, Englewood Cliffs, NJ.

Thiel M., Macaya E.C., Acuña E., Arntz W.E., Bastias H., Brokordt K., Camus P.A., Castilla J.C., Castro L.R., Cortés M., Dumont C.P., Escribano R., Fernandez M., Gajardo J.A., Gaymer C.F., Gomez I., González A.E., González H.E., Haye P.A., Illanes J., Iriarte J.L., Lancellotti D.A., Luna-Jorquera G., Luxoro C., Manriquez P.H., Marín V., Muñoz P., Navarrete S.A., Perez E., Poulin E., Sellanes J., Sepúlveda H.H., Stotz W., Tala F., Thomas A., Vargas C.A., Vasquez J.A., Alonso Vega J.M. (2007) The Humboldt Current system of northern and central Chile. Oceanographic processes, ecological interactions and socioeconomic feedback. Oceanography and Marine Biology: an Annual Review, 45, 195-345. 